\title{
Algal bloom inhibition through cobalt nano particles to control Oscillatoria growth in fresh water lakes
}

\author{
Shoaib Shariati * \\ Lecturer in Biology Department, Education Faculty, Parwan University, Afghanistan. \\ Publication history: Received on 13 May 2020; revised on 15 May 2020; accepted on 18 May 2020
}

Article DOI: https://doi.org/10.30574/gscarr.2020.3.2.0035

\begin{abstract}
Cobalt nano particles (CoNPs) were synthesized and tested against microalgae isolated from fresh water cyanobacterial blooms by assessing the effects on growth rate, biomass concentration and biochemical parameters. Oscillatoria was identified as the predominant isolate from algal blooms and treated with varying concentrations $(1,2,3,4$ and 5 mg L1) of CoNPs. Steady decline in the growth rate of microalgae was observed at the end of 5 days indicating the toxicity of CoNPs on microalgal growth. At the end of cultivation period, $88 \%$ of reduction in biomass concentration of Microcystis and Oscillatoria were observed at $5 \mathrm{mg} \mathrm{L}^{-1}$ of CoNPs. Both protein and carbohydrate contents of the microalgae were reduced with increasing concentration of nano particles. Based on the findings, this study demonstrates the efficiency of cobalt nano particles (CoNPs) on inhibition of fresh water algal blooms thereby reducing the eutrophication problem.
\end{abstract}

Keywords: Microalgae; Nano particles; Algal bloom; Oscillatoria; Cobalt nanoparticles

\section{Introduction}

Bloom control is the most challenging and controversial aspect of algal bloom management. The concept refers to actions taken to suppress or destroy algal blooms -to directly intervene in the bloom process. This is one area where algal bloom science is rudimentary and slow moving [1]. There are five general categories or strategies that can be used to combat or suppress an invasive or harmful species. These include: mechanical, biological, chemical, genetic and environmental control. Several of these have been applied to algal blooms species. For example, one form of mechanical control is the removal of algal bloom cells from the water by dispersing clay over the water surface [2, 3]. The clay particles aggregate with each other and with algal bloom cells, removing those cells through sedimentation. In other areas, the cost/benefit rationale is not as clear, and considerable effort will be required to bring research to direct application. For example, research on clay mitigation has proceeded quite far in countries such as the US [4, 5] but a significant barrier exists with respect to the ability to obtain permits, environmental clearances and funds to employ this strategy on more than an experimental scale.

Over the last few years, nanotechnologies have been developed in several directions attracting major government and commercial investments and considerable academic interests. Nanoparticles (NPs) are widely used in different fields like cosmetics for sunscreens based on its UV absorbent property, self-cleaning surfaces and paints, solar cells, and catalysis stand on the photocatalytic effect $[6,7]$. The latter property of NPs has inspired new promising technologies for water and air purification systems. Such a semi-conductive effect is due to the specific electronic structure and depends mainly on the concentration, dimension of the particles and crystal structure.

Nanoparticles can be used as an alternative to antibiotics as there are a number of advantages [8]. For instance, nanoparticles of metals with the size of $10 \mathrm{~nm}$ and less have high reactivity and can react with other substances practically without complementary energy. A share of surface atoms in nanoparticles is considerably greater than in

\footnotetext{
${ }^{*}$ Corresponding author: Shoaib Shariati
} 
bulk material and increases with reduction of particle size. Chemical bonds of nanoparticles surface atoms are not compensated and it results in appearance of new electrical, chemical, mechanical, toxic and other properties. At the same time the advantages with nanoparticles are their safety and biocompatibility [9]. The application of nanoscale materials and structures, usually ranging from 1 to 100 nanometer [nm], is an emerging area of nanoscale and nanotechnology. Nanomaterial may provide solutions to technological and environmental challenges in the areas of solar energy conversion, catalysis, medicine, water treatment and agricultural application [10]. Nanomaterial often show unique and considerably changed physical, chemical and biological properties compared to their macro scaled counterparts. Methods of preparation of metal nanoparticles are quite diverse. Besides traditional methods of their production like mechanical milling, spray pyrolysis, chemical precipitation and vapor deposition, new methods based on chemical reduction of metal salts using various reducing agents have been developed last years. These chemical methods have been mostly used for production of metal nanoparticle because they provide an easy way to synthesize nanaoparticles in solution and control of particle size.

The occurrence of algal blooms in eutrophic freshwater, brackish and marine ecosystems is receiving increasing attention worldwide as a major ecological and potential health problem. Toxic cyanobacteria bloom may cause a multitude of water quality problems, including unpleasant odors, dissolved oxygen depletion, reduced water transparency and increased pH [11]. Furthermore, they can produce several potent toxins and the presence of these compounds in drinking and bathing water supplies poses a serious hazard to human health. The control and management of algal blooms is important and thus there is great need for introduce efficient methods in order to minimize detrimental ecological and human health impacts of toxic algal bloom. This study was focused to synthesize cobalt nanoparticles using chemical reduction method and determination of growth inhibitory effect of cobalt nanoparticles against fresh water algal blooms.

\section{Methodology}

\subsection{Collection of Microalgae}

Algal blooms were collected from Qargha reservoir $\left(34.558585^{\circ} \mathrm{N}, 69.131281^{\circ} \mathrm{E}\right)$, Afghanistan. Latex gloves were used and scraping utensil (or pair of tweezers) to scrape/pluck the sample from the streambed. A small plastic bag was used for transporting algae to the laboratory. The algal samples were stored in a refrigerator until use and formalin (1/10) was used for long term preservation.

\subsection{Identification of algal strains}

Normal compound microscopes (Lawrence and Mayo) were used to analyze the algal samples of magnifications of 10X and 40X. 2-3 drops of algae-rich water from the plastic container was transferred to the glass slide along with small bits of filaments, tufts and mats. The samples were teased as much as possible and samples were kept wet to ensure there is always water on the slide and covered with cover slip. Identification of the algal samples to genus level was done with the aid of standard protocols.

\subsection{Sub culturing}

The serial transfer of single algal cultures into new medium was performed in a laminar air flow hood. An aliquot of the culture suspension was inoculated into fresh medium using a Pasteur pipette and $1 \mathrm{~mL}$ bulb. Cultures $\left(2-4 \times 10^{4}\right.$ cells $/ \mathrm{ml}$ ) were maintained in a single room having approximately 500 square feet of floor space. The temperature of the room was kept at $20 \pm 1{ }^{\circ} \mathrm{C}$ using an air conditioner. The relative humidity was kept at $31 \pm 1 \%$, the flasks were shaken by hand and randomly placed in a growth cabinet $\left(27 \pm 1^{\circ} \mathrm{O}, 12: 12 \mathrm{~h}\right.$ light/dark cycle, Philips TL $40 \mathrm{~W}$ cool white fluorescent lighting, $140 \mu \mathrm{mol}$ photons $/ \mathrm{m}^{2} / \mathrm{s}$ ) for $15-20$ days. Aeration was done for 8 hours daily using aquarium motor. Cultivation was done simultaneously in open systems by exposing the culture bottles to natural sunlight with aeration.

\subsection{Synthesis of Cobalt Nano particles (CoNPs)}

Cobalt nanoparticles were synthesized by dissolving $2 \mathrm{gm}$ of $\mathrm{CoCl}_{2} .6 \mathrm{H}_{2} \mathrm{O}$ in $20 \mathrm{ml}$ of water by constant stirring [12]. This was followed by adding $100 \mathrm{ml}$ of $7.2 \%$ sodium succinate $(7.2 \mathrm{~g}$ in 100 into $20 \mathrm{ml}$ of Cobalt chloride solution and heated at $70^{\circ} \mathrm{C}$ for 10 minutes. Polyvinyl alcohol solution was prepared by dissolving $0.1 \mathrm{gm}$ of PVA in $10 \mathrm{ml}$ of water and added to the above mixture. The reaction mixture was heated for 5 minutes. Hydrazine hydrate was drop-wise added with constant stirring. The solution was filtered through Whatman filter paper and washed several times with deionized water and dried in overnight at $120^{\circ} \mathrm{C}$ temperature. The dried powder was collected and sample was characterized using spectrophotometer and electron microscope. 


\subsection{Specific growth rate and Biomass productivity}

Specific growth rate $(\mu)$ of the microalgae was calculated according to the following formula.

$$
\mu=\frac{\ln \left(\mathrm{N}_{\mathrm{t}} / \mathrm{N}_{0}\right)}{\mathrm{T}_{\mathrm{t}}-\mathrm{T}_{0}}
$$

Where, $\mathrm{N}_{t}$ and $\mathrm{N}_{0}$ are the dry cell weight concentration $\left(\mathrm{g} \mathrm{L}^{-1}\right)$ at the end $\left(\mathrm{T}_{t}\right)$ and start $\left(\mathrm{T}_{0}\right)$ of $\log$ phase respectively.

Biomass $\left(\mathrm{g} \mathrm{L}^{-1}\right)$ of microalgae grown in the presence of metal nanoparticles was determined by measuring the optical density of samples at $600 \mathrm{~nm}\left(\mathrm{OD}_{600}\right)$ using UV-Vis spectrophotometer. Biomass concentration was then calculated by multiplying $\mathrm{OD}_{600}$ values with 0.6 , a predetermined conversion factor obtained by plotting $\mathrm{OD}_{600}$ versus dry cell weight (DCW). DCW was determined gravimetrically by centrifuging the algal cells $(3,000 \times \mathrm{g}, 10 \mathrm{~min})$ and drying.

$$
\text { Biomass concentration }=\mathrm{OD}_{600} \times 0.6
$$

The biomass productivity (g L $\mathrm{d}^{-1}$ ) was calculated according to Eq. (2)

$$
\text { Biomass productivity }=\left(\mathrm{B}_{\mathrm{t}}-\mathrm{B}_{0}\right) / \mathrm{d}
$$

where $\mathrm{B}_{\mathrm{t}}$ was the final biomass concentration, $\mathrm{B}_{0}$ is the initial biomass concentration and $\mathrm{d}$ is the cultivation time.

\subsection{Determination of Protein content}

The extraction of proteins was performed using alkali method. An aliquot ( $2 \mathrm{~mL}$ ) of sample was centrifuged, $1 \mathrm{~mL} 0.5 \mathrm{~N}$ $\mathrm{NaOH}$ was added to the pellet and extracted at $80^{\circ} \mathrm{C}$ for $10 \mathrm{~min}$ with occasional stirring. After cooling and centrifugation, the supernatant was transferred to a new tube. The alkali extraction was repeated 3 times. The final repeat was heated at $100{ }^{\circ} \mathrm{C}$ for $10 \mathrm{~min}$ for complete extraction of residual proteins. All the three extractions were pooled and mixed well before analysis. The protein content in the extract was estimated using Lowry's method [13].

\subsection{Determination of Carbohydrate content}

Cellular carbohydrates were estimated using the anthrone method [14] after hot alkaline extraction [15]. Briefly,

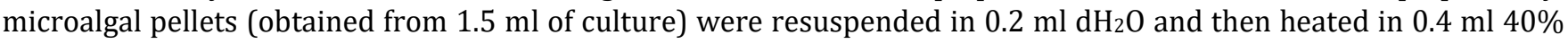
(w/v) KOH at $90^{\circ} \mathrm{C}$ for $1 \mathrm{~h}$. After cooling down, $1.2 \mathrm{ml}$ cold absolute ethanol was added and stored in a fridge at $-20^{\circ} \mathrm{C}$ overnight. The sample was spun down and the supernatant was discarded. The pellet was then resuspended in $1.5 \mathrm{ml}$ $\mathrm{H}_{2} \mathrm{O}$. The sample was then reacted with anthrone reagent and a high concentration of sulphuric acid. An aliquot ( $\left.0.2 \mathrm{ml}\right)$ of sample was mixed and vortexed with $0.4 \mathrm{ml}$ of pre-chilled $75 \% \mathrm{H}_{2} \mathrm{SO}_{4}$ solution in a test tube. To this mixture $0.8 \mathrm{ml}$ of the anthrone reagent $\left(2 \mathrm{~g} \mathrm{l}^{-1}\right.$ in $75 \% \mathrm{H}_{2} \mathrm{SO}_{4}$, freshly prepared) was added and subsequently boiled at $100{ }^{\circ} \mathrm{C}$ for 15 min. After cooling, the absorbance was read at $578 \mathrm{~nm}$ by using a spectrophotometer. Blank absorbance of the sample was read by reacting $0.2 \mathrm{ml}$ sample with $1.2 \mathrm{ml}$ of $75 \% \mathrm{H}_{2} \mathrm{SO}_{4}$ without the anthrone reagent. The amount of carbohydrate was estimated using a standard curve created using D-glucose.

\section{Results and discussion}

From the algal samples collected, Oscillatoria was identified (Fig-1) as the predominant species and was used in this study to determine the inhibition studies. 


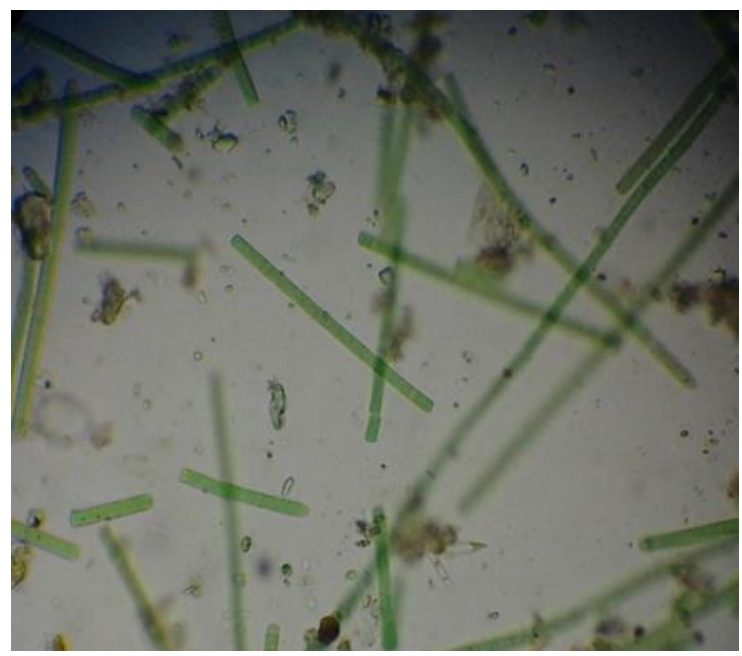

Figure 1 Oscillatoria isolated from the study
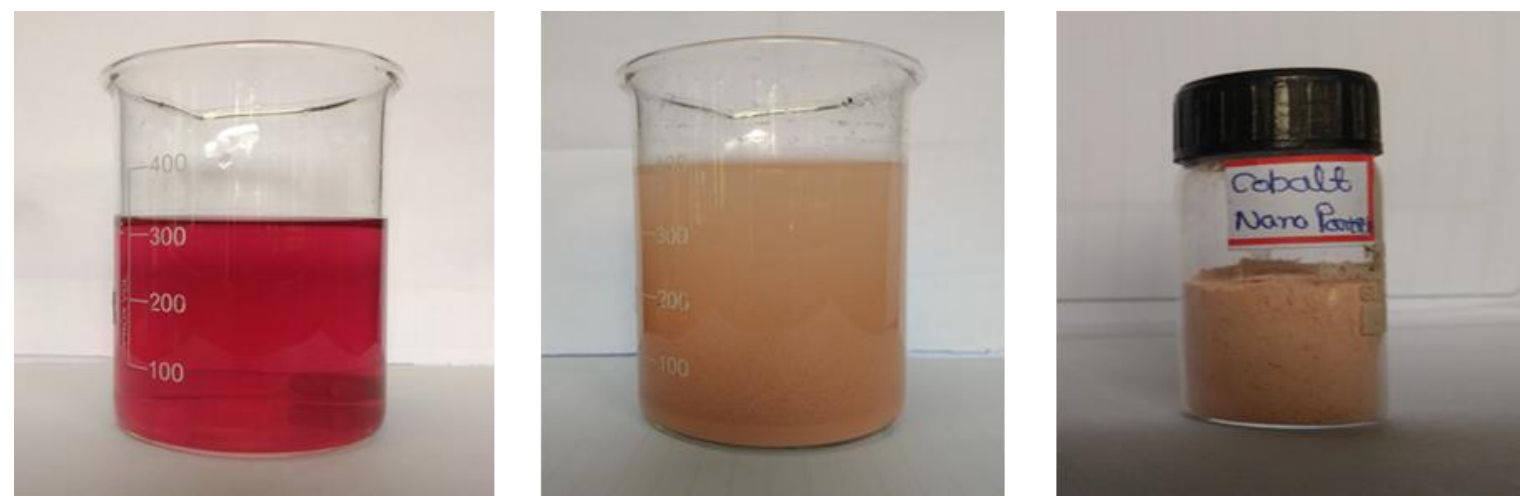

Figure 2 Cobalt Nanoparticle synthesis
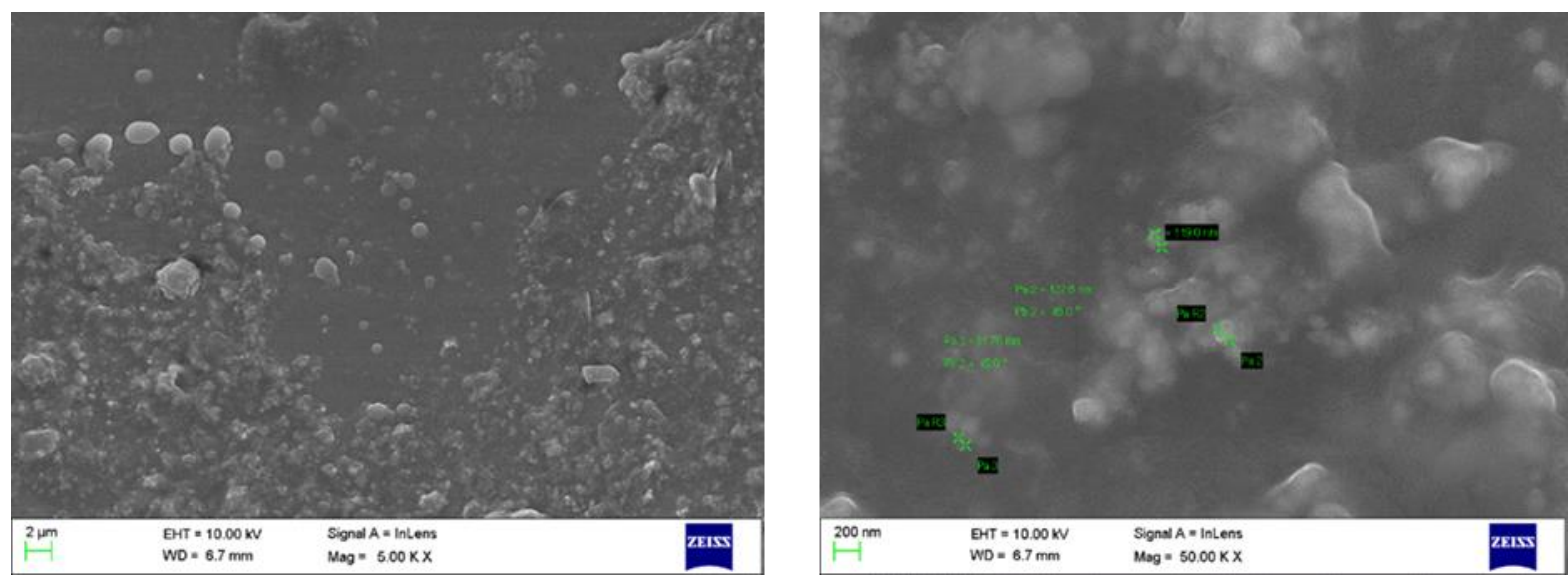

Figure 3 SEM analysis of Cobalt Nanoparticles

The above image (Fig-3) shows the SEM images of nanocobalt particles. The SEM image confirms that synthesized CoNPs are spherical in shape and have a smooth surface morphology. It is also apparent that resulting NPs are more and less uniform in size and shape. The SEM image shows that CoNPs have a good size distribution with an average size of 75$90 \mathrm{~nm}$.

The engineered silver nanoparticles exhibit a maximum absorption at $410 \mathrm{~nm}$ and size range between $75-90 \mathrm{~nm}$ and confirmed by using UV-visible spectrophotometer and SEM. Previous studies have suggested that adsorption of nanoparticle to the cell surface and NPs located inside cell wall and plasmic membrane of algae could be altered the 
cellular acquisition of essential nutrients, either through clogging of the walls or nutrient adsorption and activated to be more toxic to cells, leading to cell death.

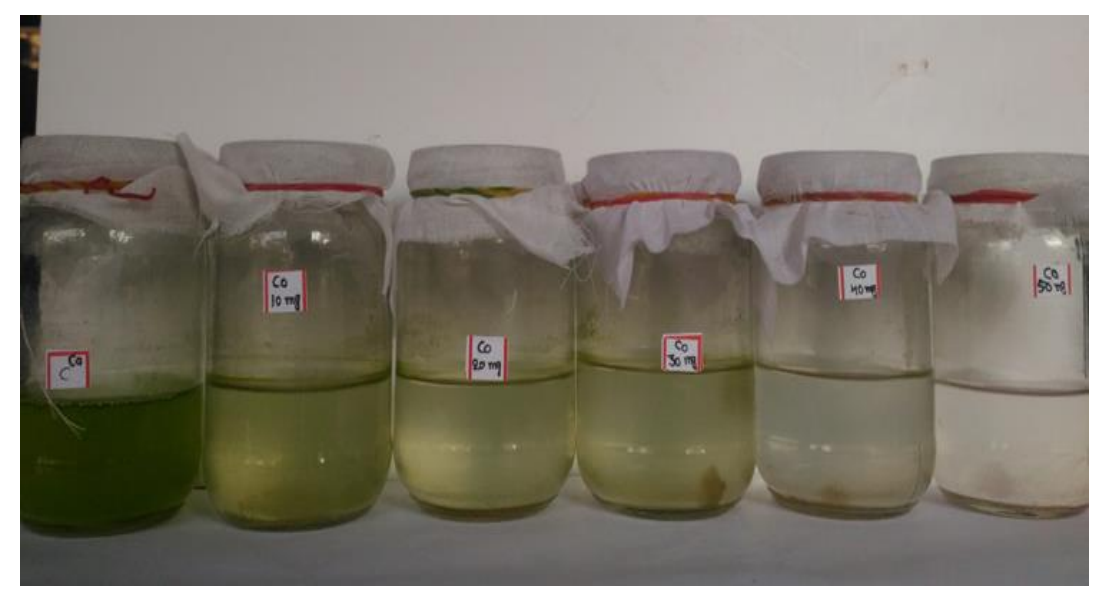

Figure 4 Effect of CoNPs on growth of Oscillatoria

In order to evaluate the effect of cobalt nanoparticle on growth of Oscillatoria strains, $3 \mathrm{ml}$ of microalgal suspension with exponential growth phase (5-6 d old) was harvested from stock cultures and was added to $150 \mathrm{ml}$ of sterilized microalgal culture medium in glass jars. Microalgal cells were exposed to increasing nominal concentration of cobalt nanoparticle including a control $\left(10,20,30,40,50 \mathrm{mg} \mathrm{L}^{-1}\right)$. The experiment was performed in triplicate. Experiment was incubated under the same conditions (light, temperature) as mentioned in the cultivation period. Prior to experiments, to avoid metal contamination all glassware used for the culture was previously cleaned with nitric acid, rinsed several times with deionized water. All materials were autoclaved $\left(30 \mathrm{~min}\right.$ at $\left.121{ }^{\circ} \mathrm{C}\right)$ to prevent biological contamination.

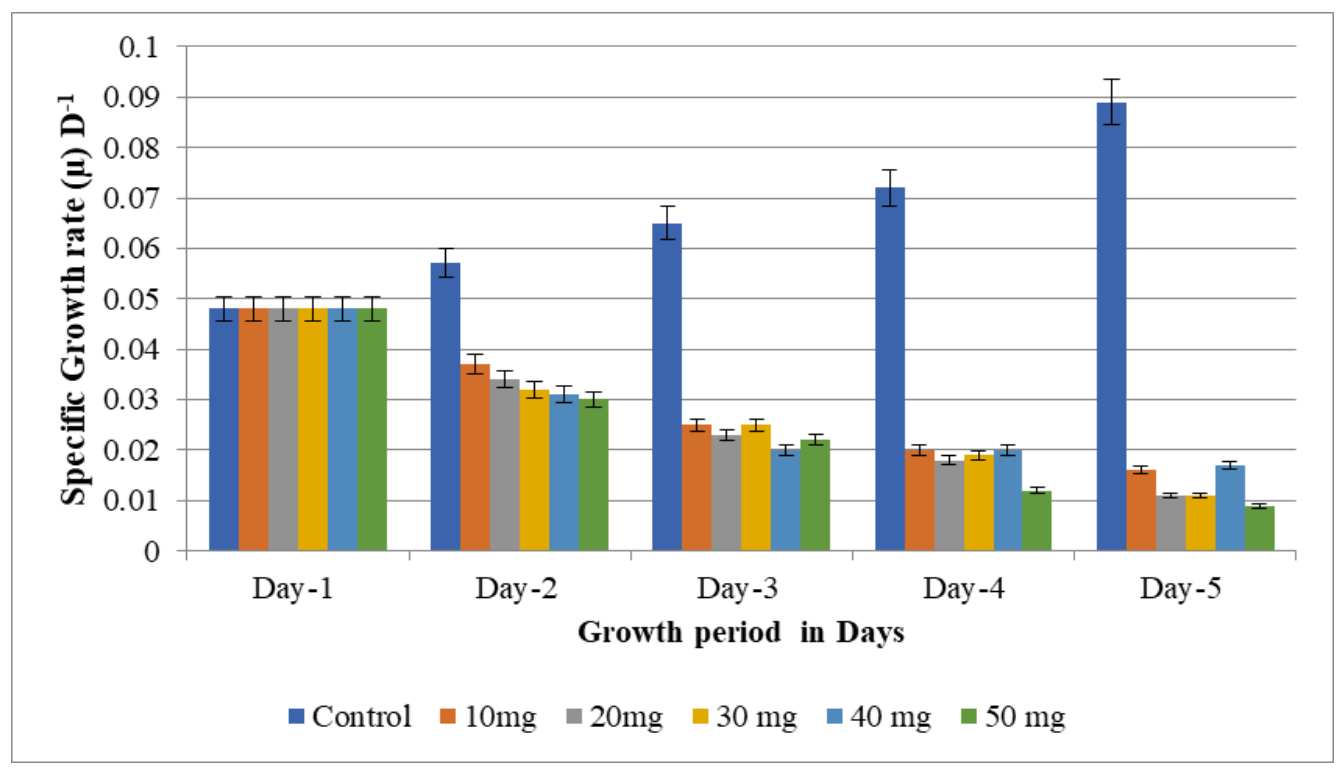

Figure 5 Specific growth rate of Oscillatoria at various concentrations of CoNPs

Specific growth rate is the measurement of microalgal growth and the presence of metal nanoparticle reduced the overall growth rate of Oscillatoria. Steady decline in the growth rate of microalgae was observed at the end of 5 days (Fig- 5) indicating the toxicity of CoNP on microalgal growth. The experiments were performed for a period of 5 days with an initial biomass concentration of $0.065 \mathrm{mg} \mathrm{L}^{-1}$. Increased CoNPs concentration reduced the biomass content of Oscillatoria which was $88 \%$ lower than initial concentration. 
Shoaib / GSC Advanced Research and Reviews, 2020, 03(02), 031-038

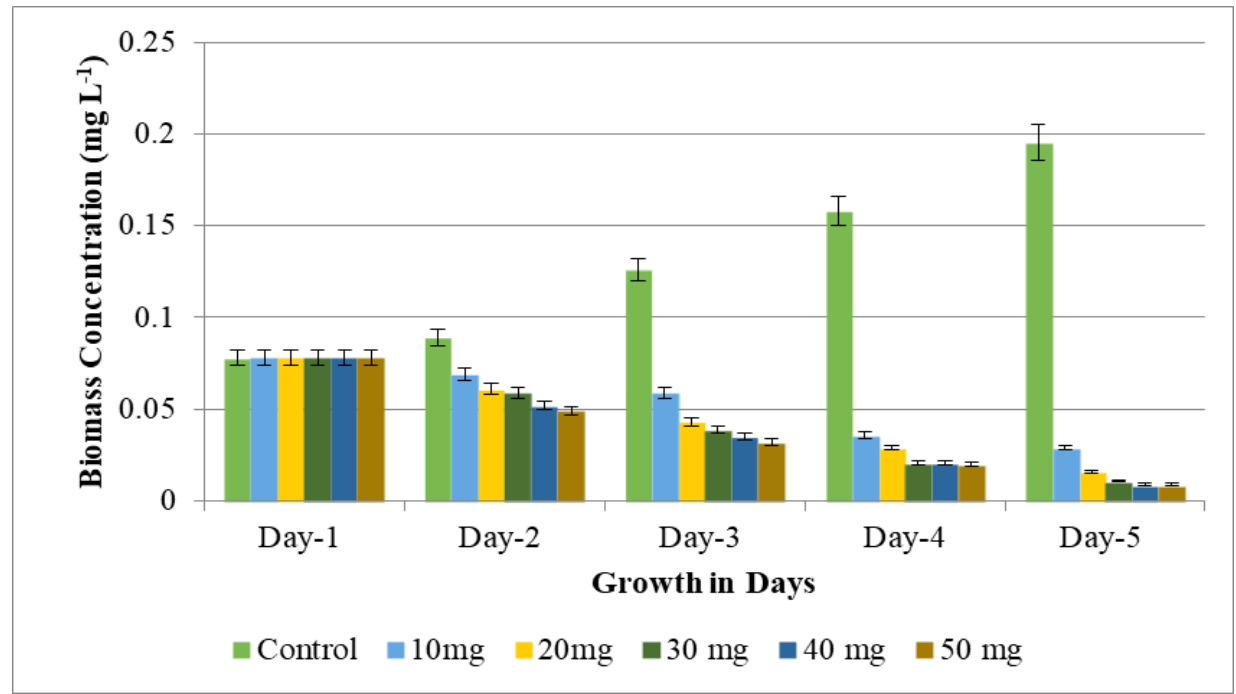

Figure 6 Biomass concentration of Oscillatoria at various concentrations of CoNPs

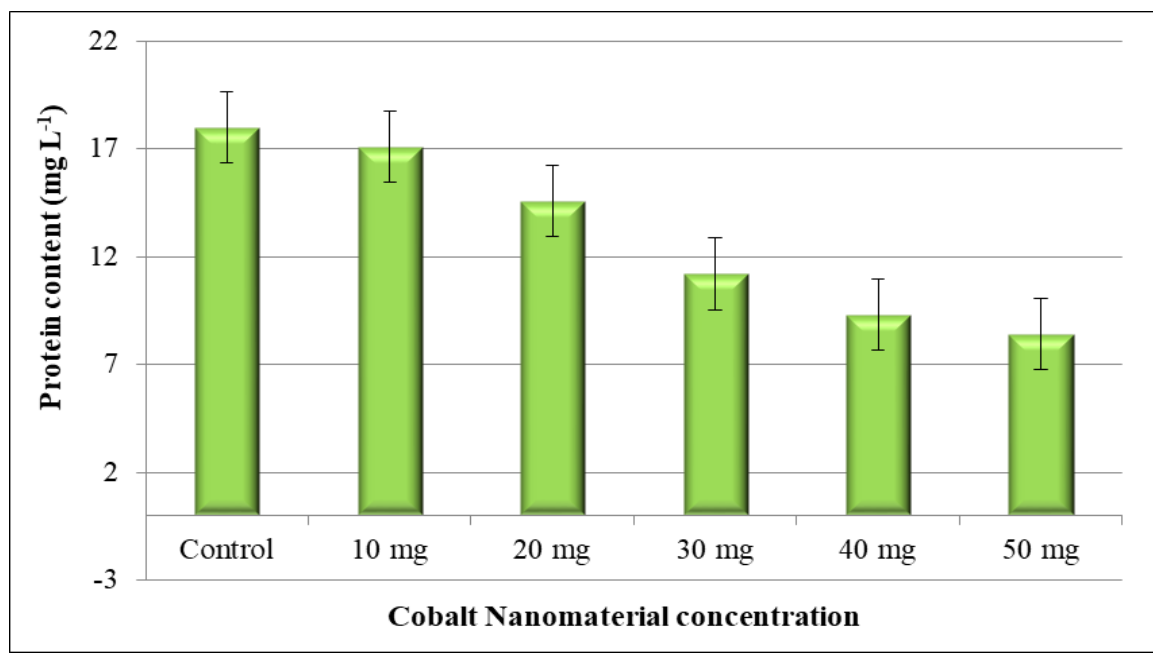

Figure 7 Protein content of Oscillatoria at various concentrations of CoNPs

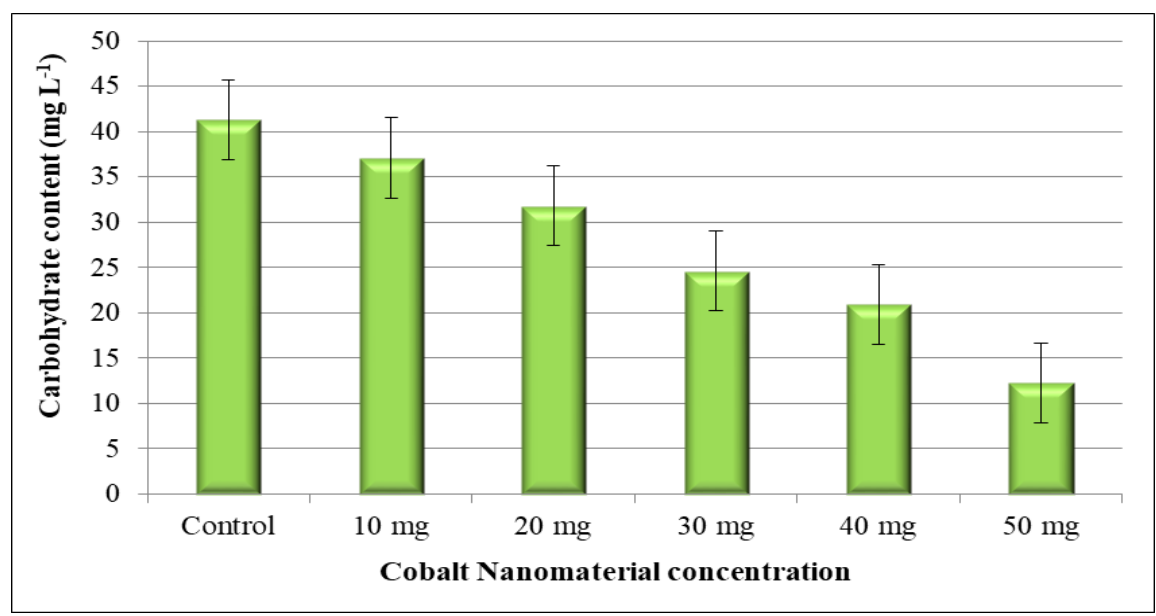

Figure 8 Carbohydrate content of Oscillatoria at various concentrations of CoNPs 
Decrease of the growth can be relatively easily determined and reflects physiological status of the algal cells [16]. Heavy metals had adverse effects on the growth of microalgae $[17,18,19]$ in cultures, same result also was found in this study, the inhibited of growth is mainly under high cobalt concentration, the growth of Oscillatoria decreased with the increasing cobalt nanoparticle concentration. From the results, it was observed that both the protein and carbohydrate content of the microalgae were decreased with higher concentrations of Co-NPs indicating its toxicity against the microalgae.

\section{Conclusion}

In conclusion, the inhibitory effect of CoNPs become greater with an increase in concentrations and suggested that the reduction in the growth rate of algae due to a decrease in algal photosynthesis caused by the inhibition of cellular components. This study demonstrates the efficiency of cobalt nanoparticles (CoNPs) on inhibition of fresh water algal blooms thereby reducing the eutrophication problem.

\section{Compliance with ethical standards}

\section{Acknowledgments}

The author is immensely grateful to Parwan University, Islamic Republic of Afghanistan to carry out this work.

\section{Disclosure of conflict of interest}

The author declares no conflict of interest.

\section{References}

[1] Andersen RA. (2005). Algal Culturing Techniques; Elsevier Academic Press: San Diego, CA, USA, ISBN 978-0-12088426-1.

[2] Na GH, Choi WJ and Chun YY. (1996). A study on red tide control with loess suspension. Korean Journal of Aquaculture, 9, 239-245.

[3] Sengco MR, Hagstrom JA, Graneli E and Anderson DM. (2005). Removal of Prymnesium parvum (Haptophyceae) and its toxins using clay minerals. Harmful Algae, 4, 261-274.

[4] Sengco MR, Li A, Tugend K, Kulis D and Anderson DM. (2001). Removal of red- and brown-tide cells using clay flocculation. I. Laboratory culture experiments with Gymnodinium breve and Aureococcus anophagefferens. Marine Ecology Progress Series, 210, 41-53.

[5] Sengco MR and Anderson DM. (2004). Controlling harmful algal blooms through clay flocculation. J Eukaryot Microbiol, 51(2), 169-172.

[6] Burke A, Ito S, Snaith H, Bach U, Kwiatkowski J and Gratzel M. (2008). The function of a TiO2 compact layer in dye-sensitized solar cells incorporating planar organic dyes. Nano Letters, 8(4), 977-981.

[7] Kaida BT, Kobayashi K, Adachi M and Suzuki F. (2004). Optical characteristics of titanium oxide interference film and the film laminated with oxides and their applications for cosmetics, Journal of Cosmetic Science, 55(2), 219220.

[8] Baker AC, Wright M, Stepanauskas R and McArthur JV. (2006). Co-selection of antibiotic and metal resistance. Trends Microbiol, 14, 176-182.

[9] Bhati-Kushwaha $\mathrm{H}$ and Malik CP. (2014). Assessment of antibacterial and antifungal activities of silver nanoparticles obtained from the Callus (stem and leaf) of Tridax procumbens L. Ind J Biotechnol, 13, 114-120.

[10] Gupta AK and Gupta M. (2005) Synthesis and surface engineering of iron oxide nanoparticles for biomedical applications. Biomaterials, 26, 3995-4021.

[11] Duong TT, Le TPQ, Dao TS, Pflugmacher S, Rochelle-Newall E, Hoang TK, Vu TN, Ho CT and Dang DK. (2012). Seasonal variation of cyanobacteria and microcystins in the Nui Coc Reservoir, Northern Vietnam. J. Appl. Phycol, 25, 1065-1075.

[12] Nazeruddin GM and Shaikh YI. (2014). Synthesis of cobalt nanoparticles by chemical routes and its antimicrobial activity. Research Journal of Pharmaceutical, Biological and Chemical Sciences, 5, 225-232. 
[13] Lowry OH, Rosebrough NJ, Farr AL and Randall RJ. (1951). Protein Measurement with the Folin Phenol Reagent. The Journal of Biological Chemistry, 193, 265-275.

[14] Gerhardt P, Murray RGE, Wood WA and Krieg NR. (1994) Methods for General and Molecular Bacteriology. ASM, Washington DC.

[15] Leyva A, Quintana A, Sanchez M, Rodriguez EN, Cremata J and Sanchez JC. (2008).Rapid and sensitive anthronesulfuric acid assay in microplate format to quantify carbohydrate in biopharmaceutical products: Method development and validation. Biologicals, 36, 134-141.

[16] Juraj P, Eliza S, Jana K, Tatiana K and Martin B. (2011). Influence of long-term exposure to copper on the lichen photobiont Trebouxia erici and the free-living algae Scenedesmus quadricauda. Plant Growth Regul, 63, 81-88.

[17] Mohammed MH and Markert B. (2006). Toxicity of heavy metals on Scenedesmus quadricauda (Turp.) de Brebisson in batch cultures. Environ Sci Pollut Res Int, 13, 98-104.

[18] Stork F, Backor M, Klejdus B, Hedbavny J and Kovacik. (2013). Changes of metal-induced toxicity by H2O2/NO modulators in Scenedesmus quadricauda (Chlorophyceae). J Environ Sci Pollut Res Int, 20, 5502-5511.

[19] Celekli A, Gultekin E and Bozkurt H. (2016). Morphological and biochemical responses of Spirogyra setiformis, exposed to cadmium. CLEAN Soil Air Water, 44, 256-262.

\section{How to cite this article}

Shoaib S. (2020). Algal bloom inhibition through cobalt nano particles to control Oscillatoria growth in fresh water lakes. GSC Advanced Research and Reviews, 3(2), 31-38. 